\title{
THE IMPACT OF INTERNATIONAL TOURIST ARRIVALS ON ECONOMIC GROWTH UNDER DENGUE FEVER RISK IN MALAYSIA
}

\author{
Chuie Hong $\operatorname{Tan}^{1} \&$ See Nie Lee ${ }^{2}$ \\ 1,2Faculty of Management, Multimedia University, Malaysia \\ (chtan@mmu.edu.my, nina_leeseenie@hotmail.com)
}

\begin{abstract}
Dengue fever has long been a public health problem in tropical and subtropical countries. The dengue virus is critical problem for international tourists with a rising number of them returning from dengueendemic countries infected with dengue fever. The aim of the study is to examine the relationship between international tourist arrivals on economic growth moderated by the rise in dengue fever cases in Malaysia from 2014 until 2020. This study was carried out using secondary monthly data for dengue fever cases, gross domestic productivity (GDP) data and data on international tourist arrivals in the country. A correlation test was used to determine the correlation between the independent, dependent and moderating variables. The results reveal a significant correlation among dengue fever cases, tourist arrivals and economic growth. In 2017 and 2018, higher international tourist arrivals lead to a lower Malaysian economic growth following a dengue disease outbreak. Furthermore, dengue fever risks show a positive relationship with international tourist arrivals and vice-versa. In line with the government's strategy to promote the Malaysian tourism industry, some prevention and recovery policies that take into consideration the number of dengue cases and economic factors should be planned.
\end{abstract}

KEYWORDS: International tourist arrivals, economic growth, dengue fever, Malaysia

\section{PURPOSE AND BACKGROUND}

Malaysia is one of the tropical countries that is plagued by dengue. In 2019, a dengue outbreak occurred in Malaysia, with some 130,385 cases reported. It was also reported that there were 336 fatalities that year. The tourism industry plays a significant role in Malaysia's economic growth. Hence, this study aims to investigate the relationship between international tourist arrivals on economic growth moderated by dengue fever cases in Malaysia.

\section{METHODOLOGY}

This study was carried out using secondary monthly data from between 2014 and 2020 for dengue fever cases, gross domestic productivity (GDP) data and data on international tourist arrivals. The E-view software was employed to test the correlation between the independent, dependent and moderating variables.

\section{FINDINGS}

The results reveal a significant correlation among dengue fever cases, tourist arrivals and economic growth. In 2017 and 2018, higher international tourist arrivals lead to a lower Malaysian economic growth following a dengue disease outbreak. Furthermore, dengue fever risks show a positive relationship with the number of international tourist arrivals and vice versa. 


\section{CONCLUSION}

Dengue infections in international tourists crop up regularly and may be linked with to other illnesses. This paper is the first to contribute to an investigation of the impact of international tourist arrivals on Malaysia's economic growth in dengue outbreak conditions.

\section{CONTRIBUTION/PRACTICAL IMPLICATIONS}

This study has prompted more government surveillance on dengue disease risks which are contagious and likely to be transmitted to more people. It has also prompted the government to put in more effort to mitigate the effects of dengue fever cases and contagion on the tourism industry and the country's economic development especially in line with the government's strategy to promote the Malaysian tourism industry, prevention and recovery policies that take into consideration the number of dengue cases and economic factors should be planned.

\section{ACKNOWLEDGEMENTS}

The authors would like to thank the financial support given by the Fundamental Research Grant Scheme, FRGS/1/2020/SSO/MMU/02/5.

\section{REFERENCES}

Dileep V. Mavalankar, Tapasvi I Puwar, Tiina M. Murtola, \& S. S. Vasan. (2019). A Preliminary Estimate of Immediate Cost of Chikungunya and Dengue to Gujarat, India. Dengue Bulletin. 2010 Dec; 34, 32-38. WHO Regional Office for South-East Asia. https://apps.who.int/iris/handle/10665/170981

Jaume Rossello, Maria Santana-Gallego \& Waqas Awan. (2017). Infectious disease risk and international tourism demand. Health Policy and Planning, 32, 2017, 538-548.

Steffen, R., deBernardis, C., Banos, A. (2003). Travel epidemiology—A global perspective. International Journal of Antimicrobial Agents, 21, 89-95. 